\title{
Problem Solving Process Research of Everyone Involved in Innovation Based on CAI Technology
}

\author{
Tao Chen, Yunfei Shao, and Xiaowo Tang \\ School of Economics and Management, University of Electronic Science and Technology of \\ China, 610054 Chengdu, China \\ \{Tao.Chen, Yunfei.Shao, Xiaowo.Tang, Chentao2008\} @uestc. edu. cn
}

\begin{abstract}
It is very important that non-technical department personnel especially bottom line employee serve as innovators under the requirements of everyone involved in innovation. According the view of this paper, it is feasible and necessary to build everyone involved in innovation problem solving process under Total Innovation Management (TIM) based on the Theory of Inventive Problem Solving (TRIZ). The tools under the CAI technology: How TO mode and science effects database could be very useful for all employee especially non-technical department and bottom line for innovation. The problem solving process put forward in the paper focus on non-technical department personnel especially bottom line employee for innovation.
\end{abstract}

Keywords: TRIZ, CAI technology, TIM, Problem solving process, Science effects database.

\section{Introduction}

The concept of the Total Innovation Management (TIM) was given by Qing-Rui Xu (2002) [1], who put forward the theoretical framework further in 2004. In his view, "TIM" theory make a difference significantly contrast to tradition innovation management theory, which innovation activities usually depend on R \& D function but other sources of innovation are generally ignored. To test and verify the theory, Innovative examples about Haier and Baosteel, Two of the Chinese leading companies was given. Zheng Gang (2004) [2] summed up the connotation of "TIM" theory as "three factors and one synergy", that is: total factor innovation, everyone involved in innovation, innovation in the entire space-time, and synergy of the three factors.

Among them, With the view of everyone involved in innovation, Innovative companies should not only consider R \& D department and technical staff are the source of innovation, all employees could take part in the work. under the requirements of everyone involved in innovation, from $\mathrm{R} \& \mathrm{D}$ personnel, marketing personnel, production and manufacturing, after-sales service personnel, managers, financial officers and so on, everyone have the possibility to be an outstanding innovator.

Obviously, in accordance with the requirements of innovation, that everyone participate positively in innovation, from the theory to practice which faced with many challenges. These challenges mainly are: how to cultivate ideal atmosphere for innovation; how to design innovative incentive mechanism; how to effectively communicate 
among employees, how to build a effective suggest system for the creative ideas; how to define innovation question accurately, If there is any tools help to produce valuable innovations more effectively etc. In general, almost all the challenges under everyone involved in innovation research can be probably divided into problem about the incentive mechanism, innovation factors synergy and innovative operation mode.

To the research of everyone involved in innovation management under Total Innovation Management(TIM), Previous papers mainly focused on the side of incentive mechanism and innovation factors synergy of Everyone involved in innovation [3-6]. Research about the innovative operation mode especially problem solving process are relative inadequate.

Prather CW \& Turrell had analysis problem-solving process in their paper (2002) [7]. They contrasted Employee suggestions system (ESS) to Creative problem-solving workshop (CPW) and put forward bottom line problem-solving process in their paper. In addition to ESS and CPW, Qing-Rui Xu (2007) [8] brought in "Mini Mini Company" (MMC) comes from "everybody is SUB" in Haier company and summarized them as the current operation mode of everyone involved in innovation. A comprehensive understanding to everyone involved in innovation operation mode under Total Innovation Management (TIM), the author think that at least it should include employee suggestion systems, innovative problem-solving process, everyone involved in innovation incentive system etc. In accordance with this classification, the employee suggestion system (ESS), the creative problem-solving workshop (CPW) focus on how to set up effective innovative suggestion system, MMC are mainly reflected in method of incentive system for innovation. No doubt that this is an important aspect of operation mode, but it is not all to operation mode, Innovative problem-solving process especially non-technical department for innovation with the requirement of everyone involved in innovation should also be considerable into operation mode Furthermore one common feature of the operation modes above mainly takes brainstorming as solving problem tool rather than scientific systematic innovative method.

Nowadays TRIZ theory is recognized as scientific systematic innovative method all over the world, Based on TRIZ theory more and more varieties of companies improve their ability of technological innovation. Computer-aided innovation (CAI) technology based on TRIZ theory has been proving it is very effective to solve innovative problems from all walks of line In this paper, based on the Theory of Inventive Problem Solving (TRIZ) and the CAI technology tools set up by TRIZ, it should be able to replenish problem solving process research under Everyone involved in innovation, particularly to non-technical department personnel especially bottom line employee for innovation.

\section{It Is Feasible and Necessary That Problem-Solving Process Based on CAI Technology}

TRIZ theory is recognized as the most ideal and systematic innovative ways today. By studying more than 2,500,000 patents, TRIZ theory classified technology innovation standard into "5 level innovation". The classification shows that the front 4 levels account for about $99 \%$ patents, most problems on the front 4 levels could be solved by known innovative solutions method. It should be noted that the first level innovation 
which comes into being merely a simple technical improvement of original technology accounts for about $32 \%$ patents. Problems in this level usually could be solved by experiments and not complicated knowledge. That mean if appropriate methods are taken, it is very likely to use the previous knowledge and skills to transform new problems into known problems and quickly obtain the solutions. In this way, TRIZ illustrate that it is entirely possible non-technical department personnel are able to solve some innovation problems.

TRIZ theory was built by studying more than 250 million high quality patents. Even though many of innovative problems could be solved by known innovative solutions methods on patents, it still has a lot of difficulties. Only searching wanted information from millions patents maybe beyond our imagination, more than to say to solve practical problems required specialized knowledge. So, without scientific search method, it is almost impossible to find any required suggestion from information database composing with many patents, scientific principles, know-how records, successful cases, the failure cases etc. One principal function of CAI technology based TRIZ theory exactly is Searching capability from mass information.

Statistics data shows that generally a technical person can only grasp about 100 nature effects, but total effects of the natural world has more than 10,000. Scientific effects database technology can help researchers to get more effects for settlement the innovation question. Scientific effects database treats nature effects as a "black box" system, which only response to specific input. That is not difficult for non-technical department personnel search nature effects by HOW To mode one function of the CAI technology. So non-technical department personnel especially bottom line employee often lack of relative knowledge and methods for innovation, but they can quickly search similar solutions by HOW To functional mode of the CAI technology. That is why CAI technology could be a powerful tool for non-technical department personnel.

\section{Problem-Solving Process Based on CAI Technology Proposed and Explained}

TRIZ theory asserts that innovation is a problem-solving process accompanied by all sorts of questions, no problems no innovation. By definition the problem exactly with tools of function analysis and brainstorm many non-standard problems will transfer to the standard questions, after that we could possible get an answer from the HOW To mode in the scientific effects database. On the basis of TRIZ problem-solving process, the author put forwards a problem-solving process which mainly concerns on how the non-technological innovation department personnel to innovate based on CAI technology as follow (Fig. 1)

The process could be divided into three major stages: the phase of analysis and identification problem, the phase of many problem-solving ideas being generated, the phase of the ideas selection and action plan. The author mainly explains to the first phase in the paper.

In the first phase, to the simple questions which employee could quickly solve by their own experiences have no necessary into the process. To relative complexity problems, the innovation group will transfer them into the standard problems according to 


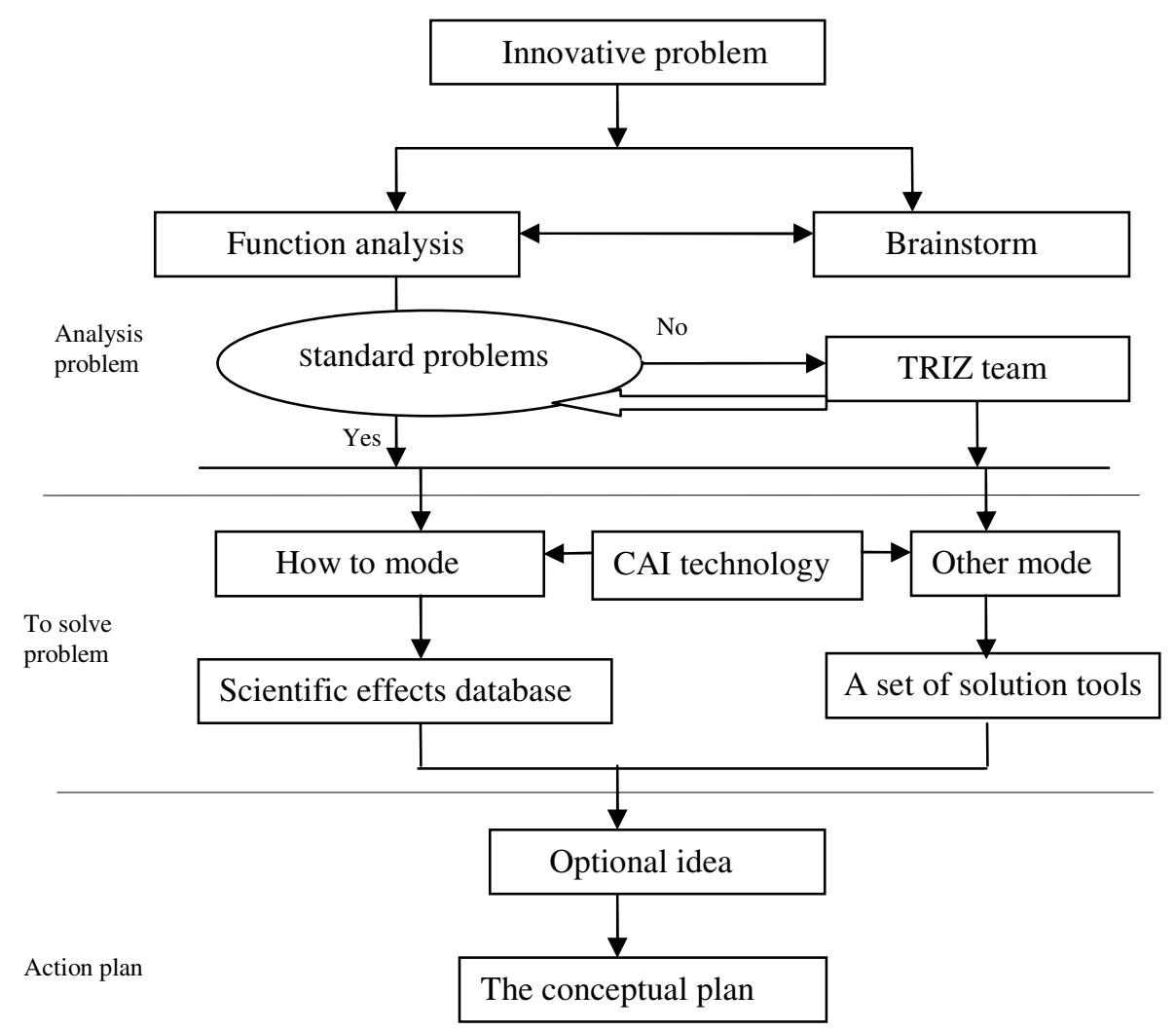

Fig. 1. Problem-solving process based on CAI technology

TRIZ definition as far as possible, make use of the method of functional analysis based on TRIZ and brainstorming. The standard problems here also have to match the requirement of HOW TO mode under CAI technology. To the standard problem which could not be easily identity by HOW TO mode, other problem-solving modes under CAI technology could be consider, such as trying to use the contradiction matrix and solving the problem by the TRIZ 40 innovative principles.

In the first phase, there is a TRIZ team, whose duty should mainly solve the problems that innovation group had no ways to define as standard problems, By re-identification to these questions, TRIZ team could try to transform them into standardized problems and feed back to the innovation group to resolve. Otherwise, solve the problems using other TRIZ tools, such as ARIZ algorithm etc. The TRIZ team could be a virtual and Informal team, which can also be a special formal department, whose core members should be TRIZ experts.

In the first phase, a very important step in the process is the functional analysis method. With the purpose to collect useful and harmful functions as much as possible and ranked according to their importance to the functions, so as to transform the most important function into standard problem identified by HOW TO mode. 


\section{Examples for Illustration of the Problem-Solving Process}

We know a computer mouse usually has two primarily useful functions, which allow users to navigate on line across the monitor and send or get information between user and computer by clicking the mouse. But in current state, a computer mouse needs space and has some weight. Besides, a connector between mouse and computer has to be established. The problem need to be solved is how to design a new mouse concept for notebook computers. As far as non-technical department personnel especially bottom line employee concerned, If they are not familiar with any kind of innovation disciplines, perhaps the solutions should be relatively divergence and very difficult to implement. Furthermore, usually it cost a lot of time.

With the help of the functional analysis based on TRIZ, we could follow some solution finding process [17] and transfer our problem into the standard problem, that is to achieve the above functions, more functions have to be introduced. The system must provide a navigation mechanism, a scroll mechanism and a click mechanism. A connection also has to be provided. Martin G. Moehrle and Sven Wenzke(2006) [16] Using one famous CAI software by Ideation International in this example leads to 12 problem formulations, such as: find an alternative way to obtain [the] (Navigate across monitor) that does not require [the](Provide location mechanism) and (Provide scroll mechanism), Or find an alternative way to obtain [the] (Connect with computer main board) that offers the following: provides or enhances [the] (Provide location mechanism), (Provide scroll mechanism) and (Provide click mechanism), does not cause [the] (Provide connection). From 12 problem formulations which we may select those with a significant leverage to solve the problem. One concept design we know well is wireless mouse as substitute of wired mouse.

Another example is: a bulbs Plant found a quality problem. The initial suspicion was given that the internal pressure of the bulbs did not meet the quality requirement. There is very little gas, only $0.1 \mathrm{~g}$ or less inside Bulbs. Obviously, weighing gas is not feasible, now using science effect database base on CAI technology to find ways to measure the internal pressure of bulbs. The problem could be described as "explore gas of bulbs to measure the internal pressure inside bulbs." and standard as "gas exploration." by functional analysis. After searching in the science effect database, some effects which match the feature of "gas exploration" could be found. ZHAN Xiang-hui (2005) [11] got the effects in the science effect database are: corona discharge, light absorption, piezoelectric effect and resonance etc. These effects have provided ideas to solve the problem. In some way, the effect "corona discharge" can be more convenient and effective to solve the issue of measuring the internal pressure of bulbs. With highvoltage on light holder there will be a corona discharge, a shape of "crown" light ray emerge. The brightness degree of light ray depends on the internal pressure within bulbs. In this way the object to measure the pressure inside the bulbs was achieved.

\section{Summary}

Although the "TIM" theory continuously improves and the theory has been practicing by domestic and foreign enterprises, in some extent, the theory is still in its infancy stages no matter from the view of theory and practice. Particularly, there is seldom technological innovation tool under "TIM" Theory to conduct technological innovation practice. 
"TIM" theory focused on theoretical research by now, On the contrary, TRIZ consists of a set of practical innovative tools, So the author assert that it should be ideal integration of TRIZ and TIM from theoretical system to practice. Issues about everyone involved in innovation are one of fundamental questions to "TIM" theory. More over operation mode should be an important issue to everyone involved in innovation and obviously that problem solving process must be contained in operation mode definitely. With requirement of everyone involved in innovation, one key question to problem solving process is how to innovate effectively especially to non-technical department personnel how they could participate in innovation and get some kind of achievements.

The above analysis demonstrate it is feasible for non-technological department personnel to solve innovation problems with the problem solving process of everyone involved in innovation based on CAI innovation technology. That means the research should improve relative theory and be valuable to practice.

\section{Acknowledgments}

This paper was under the project 2007FY140400 supported by The technological basic special project of the Ministry of Science and 2008ZR0015 supported by soft science project of Science and Technology bureau of Sichuan province.

\section{References}

1. Qingrui, X., Zida, Y., Gang, Z., et al.: Towards Capability- based Total Innovation Management (TIM): The Emerging New Trend of Innovation Management. In: Proceeding of ICMIT 2002 \& ISMOT 2002, pp. 233-223. Zhejiang University Press (2002)

2. Gang, Z.: TIM perspective on the process of technological innovation innovative elements of the comprehensive mechanism of synergy [D]. Zhejiang University, Hangzhou (2004)

3. Xie, Z.: The mechanism and management mode of all involvement innovation from tim perspective [D]. Zhejiang University, Hang zhou (2005)

4. Xu, Q.-r., Jin, C., Gang, Z.: Theoretical Trace and Framework of Overall Innovation Management. Chinese Journal of Management 3 (2006)

5. Yu, Z.-d., Li, Y., Xu, Q.-r., Wang, H.-w.: The Empirical Study on Elements of AllInvolvement Innovation Capability. Journal of Industrial Engineering/Engineering Management 2 (2006)

6. Xu, Q.-r., Jia, F.-h., Zhangshu, X., Gang, Z.: Everyone involved in innovation on total innovation management. Studies in Science of Science 12 (2003)

7. Prather, C.W., Turrell, M.C.: Involve Everyone in the Innovation Process Research. Technology Management, September-October 13-16 (2002)

8. Xu, Q.-r.: Total Innovation Management -Theory and Practice, pp. 109-113. Science Press, Beijing (2007)

9. Jin, C., Fangrui, W.: Technological innovation management methods, p. 9. Tsinghua University Press, Beijing (2006)

10. Ikovenko, S.: TRIZ and Computer Aided Inventing [R]. In: Building the Information Society: IFIP 18th World Computer Congress topical sessions (2004)

11. Zhan, X.-h., Li, Y., Jia, A.-j., Sun, Y.-s.: Scientific effects base for creative design. Journal of Engineering Design, 1 (2005) 
12. Xu, Q., Zhu, L., Zheng, G., Wang, F.: Haier's Tao of innovation: a case study of the emerging Total Innovation Management model Technology Transfer 32, 27-47 (2007)

13. Tucker, B.: Driving Growth through Innovation [M]. Berrett-Koehler Publishers Inc., San Francisco (2002)

14. Von Eric, H.: Democratizing Innovation. The MIT Press, Boston (2005)

15. Shapiro, S.: Innovation: A Blueprint for Surviving and Thriving in an Age of Change. McGraw-Hill, New York (2002)

16. Moehrle, M.G., Wenzke, S.: Exploring Problems with Function Analysis. Experimental Insights for Team Creativity and Innovation Management. Management 15(2) (2006)

17. Wenzke, S.: Flexible Design of Technical Problem Analysis with the Aid of TRIZ Instruments. DUV, Wiesbaden (2003) 